DOI: $10.29303 / \mathrm{jrpb} . v 8 \mathrm{i} 1.164$

ISSN 2301-8119, e-ISSN 2443-1354

Tersedia online di http://jrpb.unram.ac.id/

\title{
RANCANG BANGUN UNIT KONVEYOR PADA MESIN GRADING BIJI PALA (Myristica fragrans houtt)
}

\author{
Design Conveyor Unit for Grading Machine of Nutmeg Seed
}

(Myristica fragrans Houtt)

\author{
Wahyu K Sugandi ${ }^{*}$, Totok Herwanto, Mimin Muhaemin \\ Departemen Teknik Pertanian dan Biosistem, \\ Fakultas Teknologi Industri Pertanian, Universitas Padjadjaran \\ Jl. Raya Bandung-Sumedang km 21, Jatinangor, Sumedang, 45363 \\ Email ${ }^{*}$ : sugandiwahyu@gmail.com
}

Diterima: Juli 2019

Disetujui: Februari 2020

\begin{abstract}
Nutmeg (Myristica fragrans houtt) is a type of spice with high economic value on the world market. Nutmeg can be used in various industrial sectors. Nutmeg farmers in Maluku still use traditional or manual systems in the post-harvest process. The post-harvest process carried out is welding or assessment. The assessment manual has shortcomings in terms of time, uniformity, and accuracy. An automatic assessment process needs to be carried out to make it easier for nutmeg farmers to weld and increase the production of nutmeg seeds. The objectives of this research were to design Bucket-Conveyor of nutmeg grading machine and observe the maximum speed needed so that the engine capacity of $500 \mathrm{~kg} /$ day can be obtained. The function of Carrier Unit is for delivering nutmeg from the feed unit from the image box and forwarded to the dividing door. The research method used was an engineering method. The process was to determine the basic of design, functional design, structural design and technical analysis, then the performance test was carried out on the Bucket Conveyor. The results of this study were the design of nutmeg grading carrier unit shaving dimensions of length $1800 \mathrm{~mm}$, width $300 \mathrm{~mm}$ and height $600 \mathrm{~mm}$. Components of the carrier unit are bucket, pvc belt, roller and divider plate. The results of testing the capacity of the feeder unit the production capacity of $37.29 \mathrm{~kg} / \mathrm{hour}$ with rotational speed pulley $32 \mathrm{rpm}$.
\end{abstract}

Keywords: nutmeg bucket-conveyor, grading, grading machine

\begin{abstract}
ABSTRAK
Buah pala (Myristica fragrans houtt) merupakan jenis rempah dengan nilai ekonomi yang tinggi di pasar dunia. Buah pala mampu dimanfaatkan dalam berbagai sektor bidang industri. Petani biji pala di Maluku masih menggunakan sistem tradisional atau manual pada proses pasca panen. Proses pasca panen yang dilakukan yaitu pengkelasan atau grading. Grading manual memiliki kekurangan dari segi waktu, keseragaman, dan ketelitian. Proses
\end{abstract}


grading secara otomatis perlu dilakukan untuk mempermudah petani pala untuk pengkelasan dan meningkatkan hasil produksi biji pala. Tujuan dari penelitian ini untuk merancang bangun unit pembawa (Bucket-Conveyor) mesin grading biji pala dan mengetahui kecepatan maksimum yang dibutuhkan agar kapasitas mesin $500 \mathrm{~kg} / \mathrm{hari}$ dapat tercapai. Unit pembawa berfungsi untuk menghantarkan biji pala dari unit pengumpan menuju kotak citra dan diteruskan ke pintu pembagi. Metode penelitian yang digunakan adalah metode rekayasa. Proses yang dilakukan yaitu menentukan dasar perancangan, rancangan fungsional, rancangan struktural dan analisis teknik, kemudian dilakukan uji kinerja pada Bucket Conveyor. Hasil penelitian ini menunjukkan bahwa unit pembawa mesin grading biji pala memiliki dimensi panjang $1800 \mathrm{~mm}$, lebar $300 \mathrm{~mm}$ dan tinggi 600 $\mathrm{mm}$. Komponen dari unit pembawa terdiri dari bucket, belt pvc, roller, dan plat pembatas. Hasil pengujian kapasitas unit pengumpan adalah 37,29 kg/jam dengan kecepatan putar puli penggerak sebesar $32 \mathrm{rpm}$.

Kata kunci: biji pala, bucket-conveyor, grading, mesin grading

\section{PENDAHULUAN}

Pala (Myristica fragrans Houtt) merupakan salah satu komoditas dalam perdagangan rempah-rempah dunia dan merupakan produk unggulan ekspor dari Indonesia. Pusat Data dan Informasi Kementrian Pertanian (2016) mencatat Indonesia mencapai $75 \%$ dalam hal memenuhi kebutuhan pala dunia. Penyebaran pala berasal dari bagian utara Kepulauan Maluku khususnya Ambon dan Banda sehingga Indonesia dijuluki sebagai center of origin (Deryanti, dkk., 2014). Produksi buah pala di Indonesia mencapai 19,9 ribu ton per tahun (Nurdjanah, 2007). Ekspor pala ke pasar Eropa terdeteksi mengandung aflatoksin selama 16 tahun terakhir (2000-2016). Kasus ini menyebabkan $62 \%$ pala dari Indonesia ditolak (Supriadi,2015).

Aflatoksin merupakan senyawa metabolit sekunder yang bersifat toksik, diproduksi oleh strain tertentu jamur Aspergillus flavus dan A. parasiticus (Horn dkk., 2000; aflatoksin berpotensi menyebabkan kerusakan hati, pengerasan hati (cirrhosis) dan kanker hati (Hongkong Food dan Environmental Hygiene 2001 dalam Parmawati, dkk., 2006). Perlakuan penting yang dilakukan setelah pala dipanen adalah grading. Grading adalah kegiatan pemilahan suatu bahan berdasarkan permintaan pasar atau konsumen atau berdasarkan nilai yang diinginkan konsumen (Zain, dkk., 2005).

Penentuan kriteria mutu biji pala (grading) pala telah dikembangkan oleh Dinar, dkk., (2013), dengan menggunakan teknologi pengolahan citra digital. Teknologi pengolahan citra digital membutuhkan mesin pemindah untuk menghantarkan biji pala menuju citra digital yang sesuai dengan karakteristik biji pala.

Model unit konveyor mesin grading biji pala ini memerlukan perhitungan yang tepat, berdasarkan karakteristik fisik dari biji pala. Unit konveyor untuk memudahkan dalam proses mengangkut biji pala dari metering device. Biji pala yang disalurkan ke atas konveyor selanjutnya diangkut menuju posisi pengambilan citra gambar dengan mengontrol kecepatan putaran konveyor.

Jenis konveyor yang sesuai untuk memindahkan biji pala menuju pengolahan citra yaitu konveyor jenis bucket. Bucket berfungsi menghindari biji pala keluar dari konveyor dan memudahkan dalam pengambilan citra. Tujuan dari perancangan mesin ini adalah merancang bangun unit konveyor sebagai alat pemindah biji pala dari metering device menuju kotak citra pada mesin grading biji pala yang meliputi desain unit konveyor, 
komponen penggerak, dan pengujian secara fungsional.

\section{METODE PENELITIAN}

Metode penelitian yang digunakan adalah metode penelitian rekayasa, yaitu kegiatan penelitian yang tidak rutin sehingga terdapat suatu kontribusi yang baru baik dalam proses maupun bentuk (Stefanus, 2005) dapat memberikan kontribusi. Adapun prosedur penelitian seperti yang disajikan pada Gambar 1 .

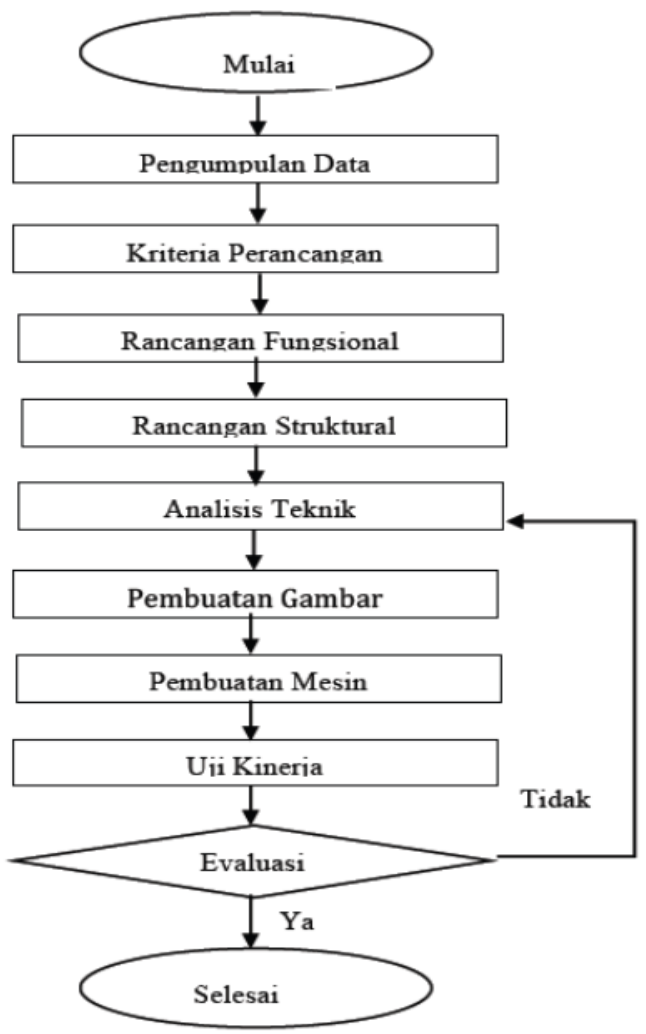

Gambar 1. Diagram alir prosedur penelitian

Alat yang digunakan untuk perancangan unit konveyor, yaitu mesin bubut, mesin frais, tachometer, clamp on meter, timbangan, pelipat plat, bor tangan, las listrik, software CAD dan kamera. Bahan yang diperlukan yaitu besi siku, pipa besi, baut, mur, bantalan, pulley, plat alumunium, cat, bucket, dan sabuk belt pvc.

Perancangan mesin grading biji pala terdiri atas beberapa komponen utama, diantaranya adalah unit pengumpan, unit konveyor, unit pengambil citra gambar, dan unit pembagi. Perancangan unit konveyor dilaksanakan berdasarkan kriteria yang meliputi pengumpulan data, penentuan kriteria perancangan, penetapan rancangan fungsional, penetapan rancangan struktural, analisis teknik, pembuatan gambar konveyor, pembuatan unit konveyor, dan uji kinerja mesin.

\section{Pengumpulan Data}

Pengumpulan data dilakukan untuk penentuan desain dan kriteria unit konveyor.

\section{Kriteria Perancangan}

Kriteria rancangan unit konveyor antara lain: kecepatan putar yang sesuai, jenis konveyor, kapasitas konveyor dan juga kriteria permukaan konveyor untuk mempermudah pengambilan citra gambar pada kotak citra.

\section{Rancangan Fungsional}

Rancangan fungsional dilakukan untuk menentukan fungsi dari setiap komponen utama yang digunakan dalam pembuatan unit konveyor mesin grading biji pala.

\section{Rancangan Struktural}

Rancangan struktural dilakukan untuk menentukan bentuk, ukuran dan juga tata letak dari setiap komponen unit konveyor mesin grading biji pala dan kesesuaian struktural.

\section{Analisis Teknik}

Analisis teknik dilakukan untuk memperhitungkan secara matematis baik gaya yang bekerja, kekuatan bahan dan juga ukuran yang sesuai dengan karakteristik biji pala agar unit konveyor beroperasi sesuai yang diharapkan.

\section{Gambar Teknik Unit konveyor}

Pembuatan gambar teknik unit konveyor dilakukan berdasarkan analisis rancangan fungsional dan rancangan struktural. 


\section{Pembuatan Unit konveyor}

Pembuatan unit konveyor dilakukan sesuai dengan gambar teknik yang telah dibuat dan rancangan baik fungsional maupun struktural.

\section{Uji Kinerja Mesin}

Uji kinerja unit konveyor dilakukan agar kinerja dari semua komponen berjalan sesuai dengan yang diharapkan, yaitu mengangkut biji pala dari bucket elevator menuju kotak citra.

\section{HASIL DAN PEMBAHASAN}

\section{Kriteria Perancangan}

Adapun kriteria rancangan unit

konveyor ini adalah sebagai berikut:

1. Jarak minimal antar biji pala, yaitu 10 cm pada tiap bucket

2. Dapat menyalurkan biji pala dari metering device menuju kotak citra pada tiap jalur

3. Kecepatan maju konveyor aalah 0,3 $\mathrm{m} /$ detik

4. Kapasitas mesin unit conveyor yang diharapkan mampu mencapai 40 $\mathrm{kg} / \mathrm{jam}$ dengan tiga jalur.

\section{Mekasime Kerja Unit Konveyor pada Mesin Grading Pala}

Biji pala yang berada di komponen penampung (Hopper) jatuh ke penyaringan berfungsi untuk memisahkan biji pala yang utuh dan pecah. Biji pala yang lolos saringan akan jatuh secara menggelinding. Biji yang lolos dipindahkan ke komponen penyalur dengan bantuan getaran untuk memaksimalkan pergerakan biji pala ke saluran pengarah (Gambar 2). Biji pala disalurkan secara horizontal melalui komponen penyalur sampai ke atas bucket konveyor. Biji pala selanjutnya dihantarkan menuju kotak citra untuk pengambilan gambar. Biji pala yang sudah melewati kotak citra pada pintu pembagi akan di salurkan untuk proses pemisahan kelas secara mekanis lalu jatuh pada keranjang biji pala.

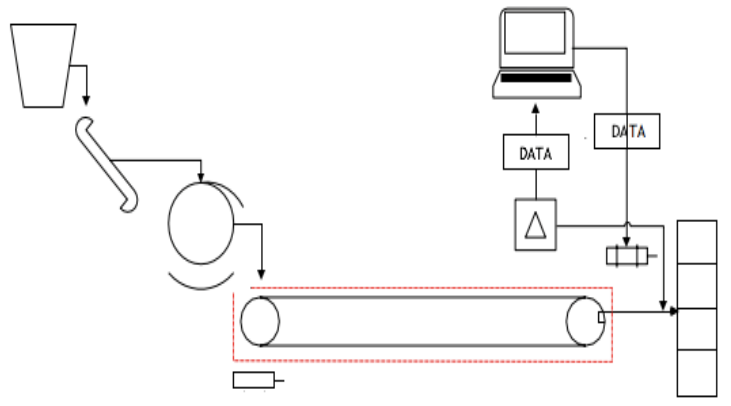

Gambar 2. Mekanisme kerja mesin grading biji pala

\section{a. Unit konveyor}

Unit konveyor pada mesin grading biji pala terdiri dari beberapa komponen utama yaitu rangka mesin, belt, bucket, dan roller (Gambar 3 dan Gambar 4). Rangka mesin berfungsi untuk menopang beban keseluruhan mesin, yaitu: unit pembawa, unit kotak citra, Komponen sistem transmisi, dan motor listrik. Rangka konveyor terdiri dari besi siku dengan ukuran $35 \mathrm{~mm} \times 35 \mathrm{~mm} \times 3 \mathrm{~mm}$. Dimensi rangka, yaitu panjang $1800 \mathrm{~mm}$, lebar $300 \mathrm{~mm}$, tinggi kolom $600 \mathrm{~mm}$.

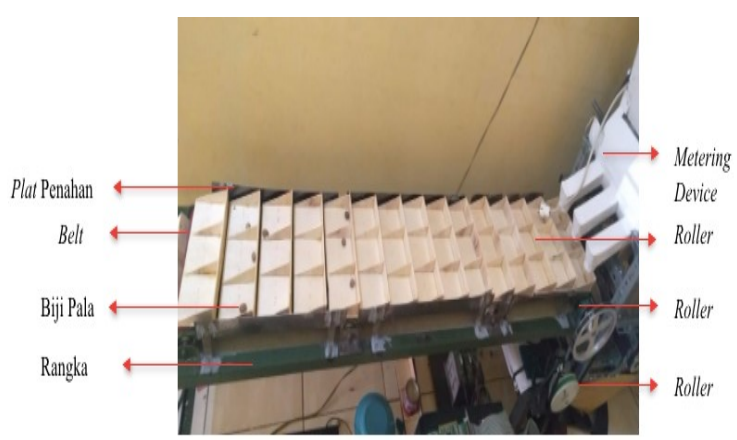

Gambar 3. Unit konveyor tampak samping

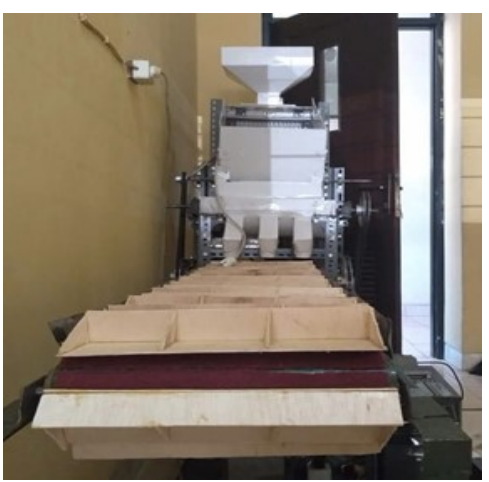

Gambar 4. Unit Konveyor tampak depan 
Panjang rangka ditentukan dari perhitungan kapasitas yang akan dicapai oleh konveyor ini, lebar rangka disesuaikan dengan panjang bucket yang akan dipasang, sedangkan tinggi kolom rangka diatur sesuai dengan nilai-nilai anthropometri, sehingga operator tidak mengalami kesulitan ketika mengatur posisi biji pala. Rangka bagian bawah dipasang dudukan untuk motor listrik.

Jenis rangka yang digunakan untuk membuat dudukan motor ini, yaitu besi "U" ukuran $80 \mathrm{~mm} \times 45 \mathrm{~mm} \times 5 \mathrm{~mm}$. Unit pembawa berfungsi untuk mengantarkan biji pala dari unit pengumpan ke pintu pembagi.

Belt yang dipasang terbuat dari material $p v c$. Belt dari material $p v c$ memiliki kelebihan yaitu tahan lama, fleksibel, mudah dikerjakan, tingkat kebisingan yang rendah dan harga yang terjangkau. Panjang belt yang dipasang sepanjang $160 \mathrm{~mm}$ dengan ketebalan $3 \mathrm{~mm}$ yang dilapisi oleh kain karpet dengan ketebalan $2 \mathrm{~mm}$. Belt dipasang untuk mempermudah pemasangan bucket (Gambar 5). Bucket yang dipasang pada konveyor berjumlah 30 buah.

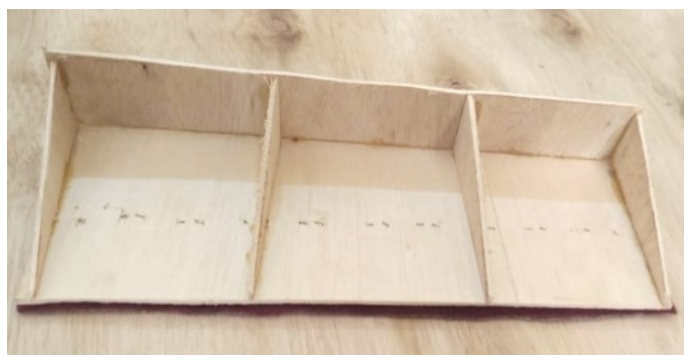

Gambar 5. Bucket

Roller pada poros penggerak terbuat dari pipa besi dengan diameter $60 \mathrm{~mm}$ dan panjang $350 \mathrm{~mm}$. Batang poros dipasang pada pipa berdiameter $18 \mathrm{~mm}$ dan panjang $500 \mathrm{~mm}$ dengan pertimbangan gaya beban yang bekerja pada poros. Batang poros berfungsi meneruskan tenaga bersamasama dengan putaran yang ditransmisikan oleh puli penggerak.

Roller dipasang 3 buah dengan jarak masing-masing $380 \mathrm{~mm}$. Satu Roller berfungsi ebagai head pulley. Roller yang dipilih memiliki diameter $60 \mathrm{~mm}$ dengan panjang $300 \mathrm{~mm}$. Posisi ketinggian head pulley dengan drive pulley haruslah sama satu dengan roller yang lain, dan pemasangan belt harus sejajar karena hal ini dapat mempengaruhi laju belt. Ketinggian roller yang tidak sama satu dengan yang lainnya menyebabkan laju belt terhambat, macet, dan dapat merusak bucket. Oleh karena itu pengencangan belt pada poros haruslah dilakukan dengan teliti dan hatihati.

\section{b. Unit transmisi}

Sistem transmisi (Gambar 6) yang dipilih untuk meneruskan daya ada konveyor ini adalah puli-sabuk. Alasan dipilihnya puli-sabuk karena jarak pusat antar puli pada sistem transmisi ini relatif dekat. Sabuk dapat meredam beban kejut ketika motor dinyalakan terutama pada motor yang berdaya besar dan lebih mudah dibongkar pasang.

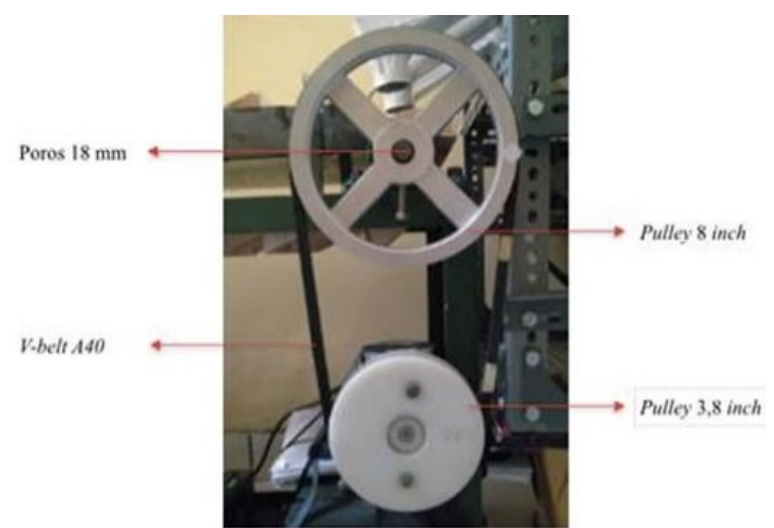

Gambar 6. Sistem Transmisi Unit Konveyor

Motor penggerak yang dipakai adalah motor stepper dengan torsi $60 \mathrm{~kg}$ dan mempunyai kecepatan putar $30 \mathrm{rpm}$. Daya ini diteruskan ke puli yang dipakai untuk putaran keluaran dari penggerak diteruskan oleh sabuk-v jenis A ukuran 40 inchi ke puli pereduksi. Ukuran sabuk-v ini ditentukan oleh diameter kedua puli yang dihubungkannya dan jarak antar pusat puli. Jarak antar pusat puli motor dan puli 
pereduksi sepanjang $300 \mathrm{~mm}$. Puli pereduksi yang dipakai yakni puli jenis A satu jalur sabuk, berdiameter 8 inchi. Diameter puli pereduksi ini ditentukan dari kecepatan linier belt yang diinginkan, jika diameter puli pereduksi diperkecil maka kecepatan linier belt semakin cepat, sebaliknya jika kecepatan linier belt ingin lebih lambat maka diameter puli pereduksi harus diperbesar. Posisi puli perduksi berada pada sumbu poros yang sama dengan roller, seperti yang disajikan pada Gambar 6.

\section{Kebutuhan Daya Penggerak}

Kebutuhan daya penggerak butuhkan untuk mengetahui daya digunakan pada unit konveyor. Pengukuran kebutuhan daya menggunakan clamp meter. Pengukuran dilakukan sebanyak 5 kali ulangan untuk setiap jenis biji pala dengan kecepatan putar untuk konveyor yaitu $32 \mathrm{rpm}$ seperti yang disajikan pada Tabel 1.

Tabel 1. Kapasitas aktual mesin konveyor

\begin{tabular}{ccc}
\hline Ulangan & \multicolumn{2}{c}{ Daya (watt) } \\
\cline { 2 - 3 } & Tanpa Beban & Dengan beban \\
\hline 1 & 23,72 & 24,24 \\
2 & 24,34 & 24,96 \\
3 & 25,32 & 25,32 \\
4 & 23,38 & 24,28 \\
5 & 23,00 & 23,52 \\
\hline Rata-rata & 23,93 & 74,70 \\
\hline
\end{tabular}

Berdasarkan data pengukuran daya aktual diketahui kebutuhan daya konveyor pada saat kondisi beban kosong, yaitu $0,23 \mathrm{~kW}$ sedangkan pada saat kondisi beban penuh kebutuhan daya $0,25 \mathrm{~kW}$. Hasil ini menunjukkan adanya peningkatan kebutuhan daya akibat adanya daya yang bekerja untuk proses pengantaran biji pala sebagai beban walaupun tidak signifikan. Sedangkan motor listrik yang digunakan pada konveyor memiliki daya sebesar 1,854 $\mathrm{kW}$, sehingga cukup untuk memenuhi kebutuhan daya mesin yakni 3,9 inchi dan diameter roller penggerak (D3) yang digunakan sebesar $70 \mathrm{~mm}$ dengan besar puli poros

\section{Analisis poros}

Poros utama yang dipasang pada mesin bucket conveyor terdapat dua buah, yaitu poros driver dan poros driven. Poros driver merupakan poros tempat puli pereduksi dipasangkan yang letaknya berkaitan langsung dengan putaran motor penggerak. Poros driven adalah poros yang sifatnya menunjang putaran poros driver sehingga membentuk lintasan bucket conveyor. Diameter poros driver sebesar 18 $\mathrm{mm}$ dan diameter poros driven sebesar 60 $\mathrm{mm}$.

\section{Analisis Pin}

Pin merupakan komponen mesin yang berfungsi untuk mengencangkan bagian mesin agar tidak bergeser. Berdasarkan hasil perhitungan diameter pin minimum yang dapat digunakan pada poros puli pereduksi adalah $4,49 \mathrm{~mm}$, sedangkan pin yang dipasang pada kenyataannya adalah 5 $\mathrm{mm}$. Ukuran diameter pin yang digunakan lebih besar dari diameter minimal hasil perhitungan, maka pin aman.

\section{Analisis Bearing}

Bantalan atau bearing berfungsi sebagai penopang gaya yang bersumber dari putaran poros dan komponen mesin. Putaran yang terjadi dapat berlangsung secara halus dan aman. Bantalan transmisi yang digunakan pada poros yaitu Pillow Block Bearing jenis UCP P205 sebanyak 2 buah dengan spesifikasi kapasitas nominal dinamik spesifik $1.100 \mathrm{~kg}$.

\section{Defleksi Rangka}

Besar lendutan yang dihasilkan pada rangka bagian atassebesar 0,076 $\mathrm{mm}$. berdasarkan besar nilai lendutan yang dihasilkan dapat menyangga rangka dengan aman.

Menurut Singer (1995), lendutan yang terjadi pada rangka tidak bisa 
melebihi 1/300 panjang rangka tersebut. Adapun panjang baris bagian atas adalah $300 \mathrm{~mm}$, dengan demikian 1/300 panjangnya adalah $1 \mathrm{~mm}$. Lendutan yang terjadi lebih kecil dari batas yang diizinkan, maka rangka dapat menyangga beban dengan aman. Besarnya lendutan pada rangka dudukan motor stepper bagian bawah adalah $0,0051 \mathrm{~mm}$. Jika lendutan yang terjadi lebih kecil dari batas yang diizinkan, maka rangka bagian bawah juga dapat menopang beban dengan aman.

Beban kritis yang mampu ditopang oleh kolom rangka adalah 51737,4 N, adapun beban aman adalah Fcr $>$ P. Jika Beban yang ditopang oleh kolom lebih kecil dari beban aman, maka kolom rangka telah memenuhi kelayakan teknis dan aman untuk digunakan.

\section{KESIMPULAN}

Adapun kesimpulan yang diperoleh dari penelitian ini adalah sebagai berikut:

1. Unit konveyor mesin grading biji pala telah berhasil dibuat untuk menghantarkan biji pala satu persatu secara konstan dari conveyor ke pintu pembagi dengan dimensi 1500 $\mathrm{mm}$ x $600 \mathrm{~mm}$ x $300 \mathrm{~mm}$.

2. Kecepatan putar yang paling optimal antara metering device dan penggetar dan konveyor terhadap kapasitas yang dihasilkan adalah $17 \mathrm{rpm}, 530 \mathrm{rpm}$ dan $32 \mathrm{rpm}$.

3. Kapasitas aktual rata-rata unit konveyor mesin grading biji pala yang dirancang mencapai kapasitas produksi $37,29 \mathrm{~kg} / \mathrm{jam}$ sebesar 214,2 butir/menit.

2. Hasil analisis jatuhan biji pala di atas bucket lubang 1 cenderung jatuh ke bagian dalam kanan, lubang 2 cenderung jatuh di atas bucket bagian dalam tengah, dan lubang cenderung pada bagian dalam kiri.

3. Total kebutuhan daya rata-rata unit konveyor pada kondisi tanpa beban sebesar $0,23 \mathrm{~kW}$, sedangkan dengan beban sebesar $0,25 \mathrm{~kW}$.

\section{DAFTAR REFERENSI}

Deryanti, T., Ervizal, A.M., \& Rinekso, S. (2014). Konservasi pala (Myristica fragrans Houtt) suatu analisis tri stimulus amar pro-konservasi kasus di kabupaten Bogor. Media Konservasi, 19(1), 47-56.

Dinar, Latifa. (2013). Kajian Standar Nasional Indonesia Biji Pala. Jurnal Standardisasi, 15 (2), 83-90.

Horn, B.W., R.L. Greene, \& J.W. Dorner. (2000). Inhibition of aflatoxin B1 production by Aspergillus parasiticus using nonaflatoxigenic strains: role of vegetative compatibility. Biological Control, 17, 147-154.

Nurdjanah, N. (2007). Teknologi Pengolahan Pala. Badan Penelitian dan Pengembangan Pascapanen Pertanian. Litbang Kementrian Pertanian RI.

Parmawati, R., Widodo, P., Budiarti, U., \& Handaka. (2006). The role of postharvest machineries and packaging in minimizing aflatoxin contamination in peanut. Indonesian J. Agric. Sci., 7(1), 15-19.

Pusat Data dan Informasi Kementrian Pertanian. (2016). Outlook Pala Komoditas Pertanian. Sekjen Kementrian Pertanian RI.

Singer, F. L., Andrew, P. and Darwin, S. (1995). Kekuatan Bahan (Teori Kokoh_Strenght of Material). Edisi ketiga. Jakarta: Erlangga.

Stefanus, S. (2005). Rever Engineering Teori dan Aplikasi. Semarang: Badan Penerbit Universitas Diponegoro. 
Supriadi. (2015). Aflatoxin of Nutmeg the major producer of aflatoxin. Molecular Plant Pathol., 8, 713722.
Zain, S., Suhadi, U., Sawitri, U., \& Ibrahim. (2005).

Teknik Penanganan Hasil Pertanian. Bandung: Gratuna. 